\title{
Montelukast versus fluticasone: effects on lung function, airway responsiveness and inflammation in moderate asthma
}

\author{
F. Kanniess, K. Richter, S. Böhme, R.A. Jörres, H. Magnussen
}

\begin{abstract}
Montelukast versus fluticasone: effects on lung function, airway responsiveness and inflammation in moderate asthma. F. Kanniess, K. Richter, S. Böhme, R.A. Jörres, H. Magnussen. C ERS Journals Ltd 2002.

ABSTRACT: Whether leukotriene receptor antagonists exhibit adequate antiinflammatory effects in the treatment of asthma is still a controversial issue. The aim of the present study was to perform a direct comparison of the effects of a 4-week treatment with either montelukast $(10 \mathrm{mg}$, once a day) or low-dose inhaled fluticasone $(100 \mu \mathrm{g}$ b.i.d. $)$ on functional and inflammatory parameters in steroid-naïve patients with moderate asthma.

Forty patients (forced expiratory volume in one second (FEV1), 60-80\% predicted) were studied in a double-blind, randomised, crossover design. Treatment periods were separated by 3-8 weeks of washout. At the beginning and end of each period, FEV1, airway responsiveness to inhaled methacholine (provocative concentration causing a $20 \%$ fall in FEV1 (PC20)), the level of exhaled nitric oxide (NO) and sputum differential cell counts were determined. Only short-acting $\beta_{2}$-agonists were allowed for relief of symptoms.

FEV1 increased by $0.50 \pm 0.07 \mathrm{~L}$ (mean \pm SEM) after fluticasone and by $0.37 \pm 0.07 \mathrm{~L}$ after montelukast $(p<0.001$, each), and $\mathrm{PC} 20$ by $1.33 \pm 0.13(p<0.001)$ and $0.15 \pm 0.17$ (NS) doubling doses, respectively. Correspondingly, percentages of sputum eosinophils were reduced by factor $2.7(\mathrm{p}<0.01)$ and 1.4 (nonsignificant (NS)), and the levels of exhaled NO (at $50 \mathrm{~mL} \cdot \mathrm{s}^{-1}$ ) by factor $2.1(\mathrm{p}<0.01)$ and 1.1 (NS).

These data indicate a comparable bronchodilator action of montelukast and fluticasone in patients with moderate asthma, but additional attenuation of airway inflammation by fluticasone as detectable through noninvasive methods.

Eur Respir J 2002; 20: 853-858.
\end{abstract}

Pulmonary Research Institute, Hospi-
tal Grosshansdorf, Center for Pneu-
mology and Thoracic Surgery, D-22927 Grosshansdorf, Germany.

Correspondence: H. Magnussen, Pulmonary Research Institute, Hospital Grosshansdorf, Center for Pneumology and Thoracic Surgery, Wöhrendamm 80, D-22927 Grosshansdorf, Germany. Fax: 494102601379

E-mail: magnussen@pulmoresearch.de

Keywords: Bronchial hyperresponsiveness

exhaled nitric oxide

fluticasone

induced sputum

montelukast

Received: May 112001

Accepted after revision: May 72002

Supported by GlaxoSmithKline, D20354 Hamburg, Germany.
Bronchial asthma is defined as an inflammatory airway disease characterised by intermittent to chronic airway obstruction and bronchial hyperresponsiveness to pharmacological and physical stimuli [1]. The chronic inflammation underlying the disease is, in particular, reflected in increased numbers of eosinophils within the airway wall and lumen [2]. Accordingly, the aim of anti-asthmatic therapy is been defined not only to prevent respiratory symptoms and improve lung function, but also to attenuate or abolish airway inflammation.

The most effective anti-inflammatory drugs currently known are corticosteroids, which are widely used in the treatment of asthma [1]. It is well established that corticosteroids, especially those administered via inhalation, lead to a reduction in respiratory symptoms and the frequency of asthma exacerbations, an improvement in lung function and a better longterm outcome of the patients [3].

Noninvasive procedures have been extensively used to assess airway inflammation in asthma and there is evidence that sputum eosinophils and exhaled nitric oxide (NO) are markers of asthmatic inflammation including treatment effects [4-9]. Nonspecific airway responsiveness has also been advocated for achieving this, and recent data have shown methacholine responsiveness to be inversely related to airway inflammation, whereas lung function and symptoms were not $[6,10]$.

Of the inflammatory mediators involved in asthma, cysteinyl leukotrienes are known to play a major role in the disease [11]. Therefore, appropriate receptor antagonists such as montelukast were developed, and, meanwhile, antileukotrienes became part of the recommendations for the treatment of asthma [1]. Montelukast has been shown to elicit bronchodilation and to be protective against a variety of bronchoconstrictor stimuli [12-14]. When added to inhaled corticosteroids, the result is better control of asthma compared to steroid treatment alone [15], through which the daily dose of steroids can simultaneously be reduced [16]. In addition, the compliance with oral medication once daily is superior to repeated corticosteroid inhalation [17].

Irrespective of the data indicating a significant antiinflammatory action of antileukotrienes, only a few studies have compared their effects with those of an inhaled corticosteroid under identical conditions [18]. Such a comparison, which includes a scale for the maximally achievable effects, appears to be of 
particular interest in patients with moderate asthma, as inflammation and clinical state may be dissociated in these patients. In the present study, a direct, headto-head comparison of montelukast with low-dose fluticasone was performed, assessing their effects on lung function, airway responsiveness and markers of airway inflammation and asthma control.

\section{Material and methods}

\section{Patients}

Forty nonsmoking patients with moderate, allergic bronchial asthma were included (table 1). Forced expiratory volume in one second (FEV1) and provocative concentration causing a $20 \%$ fall in FEV1 (PC20) at the beginning of treatment periods were required to be within $15 \%$ and 1.5 doubling concentrations, respectively, as compared to screening. All patients were atopic, according to the results of skinprick test, and had to show a bronchodilator effect of $>15 \%$ after inhalation of $200 \mu \mathrm{g}$ salbutamol.

None of the patients were smokers or had signs of an acute exacerbation or respiratory tract infection within 4 weeks before each visit. None of the patients had received inhaled or systemic corticosteroids within 3 or 6 months, respectively, or antihistamines or theophylline within 4 weeks. The protocol was approved by the appropriate Ethics Committee and all patients gave their written informed consent.

\section{Study design}

The study followed a randomised, double-blind, crossover design comprising a 1-2-week screening period and two 4-week treatment periods, separated by a 3-8 week wash-out interval. At the screening visit and at the start and end of treatment periods, lung function, methacholine responsiveness, the level of

Table 1.-Patient characteristics

\begin{tabular}{lc}
\hline M:F & $24: 16$ \\
Age (range) yrs & $37(18-60)$ \\
Total serum IgE IU $\cdot \mathrm{mL}^{-1}$ & $706 \pm 196$ \\
FEV1 L & $2.79 \pm 0.56$ \\
FEV1 \% pred & $74.2 \pm 10.6$ \\
FVC \% pred & $93.1 \pm 10.2$ \\
PC20 Mch mg $\cdot \mathrm{mL}^{-1}$ & $0.180 \div 1.17$ \\
Sputum eosinophils $\%$ & $4.28 \div 1.29$ \\
Tryptase in sputum pg $\cdot \mathrm{mL}^{-1}$ & $8.9 \div 1.4$ \\
Exhaled NO at $50 \mathrm{~mL} \cdot \mathrm{s}^{-1} \mathrm{ppb}$ & $51.1 \div 1.14$ \\
\hline
\end{tabular}

Data are presented as arithmetic mean \pm SEM. Geometric mean \pm SEM is given for immunoglobulin (Ig)E. For provocative concentration causing a $20 \%$ fall in forced expiratory volume in one second (FEV1) (PC20), eosinophils, tryptase and exhaled nitric oxide (NO), geometric mean \pm SEM (to be understood as a variability factor, indicated by $\div$ ) are supplied. FVC: forced vital capacity; $\%$ pred: $\%$ predicted; Mch: Methacholine; ppb: parts per billion. Concentration of exhaled $\mathrm{NO}$ at a flow rate of $50 \mathrm{~mL} \cdot \mathrm{s}^{-1}$ as interpolated from values obtained at four different flow rates. exhaled NO, and sputum composition were determined. Daily asthma symptom scores, the use of inhaled $\beta_{2}$-agonists and peak expiratory flow rates (PEF) were recorded over the whole time of the study.

Patients were instructed to inhale placebo or $100 \mu \mathrm{g}$

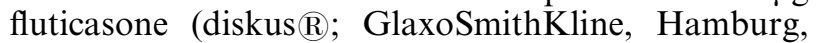
Germany) b.i.d. and to take one $10 \mathrm{mg}$ tablet of montelukast or placebo at night-time. The latter medication was taken in the evening before visits. Throughout the study, patients were allowed to inhale short-acting $\beta_{2}$-agonists (salbutamol) as rescue medication.

\section{Measurements}

Patients filled in diary cards for day and night-time symptoms, with scores from 0 (no symptoms) to 4 (maximal symptoms, severe impairment of daytime activities, no sleep during night-time), as well as the use of rescue medication. Measurements of PEF were performed in triplicate twice daily using an electronic PEF device [19].

Spirometry was performed according to European Respiratory Society guidelines [20] using a handheld spirometer. Bronchial responsiveness to methacholine was assessed using a rapid protocol [21].

For NO measurement, patients maintained predetermined expiratory flow rates $(21,33,69$ and $207 \mathrm{~mL} \cdot \mathrm{s}^{-1}$, in duplicate) against varying resistances at 20 mbar [22, 23]. Plateau values of exhaled NO were assessed (Sievers Instruments Inc., Boulder, Co, USA) and the level at $50 \mathrm{~mL} \cdot \mathrm{s}^{-1}$ derived by interpolation. The analyser was checked daily using certified calibration gas.

Sputum induction was performed as described previously [24, 25]. Cell differentials were assessed and the concentration of mast cell tryptase in supernatants was determined using the Pharmacia CAP system (Pharmacia \& Upjohn, Erlangen, Germany).

\section{Statistical analysis}

Values of FEV1, forced vital capacity (FVC), symptoms and the use of $\beta_{2}$-agonists are given as arithmetic mean \pm SEM. Values of immunoglobulin (Ig)E, sputum eosinophils, NO and tryptase are given as geometric mean \pm SEM (to be understood as factor). Mean values of diary data and PEF from the last 7 days of treatment were compared with the last 7 days of screening or wash-out periods, respectively. Comparisons within treatments were made by paired t-tests, and comparisons between treatments by analysis of variance (ANOVA) for crossover design. Carry-over effects were excluded by prior testing. Statistical significance was assumed as $\mathrm{p} \leqslant 0.05$.

\section{Results}

As indicated by ANOVA, there were no carry-over effects between treatments. Similarly, baseline values at the start of treatment periods were not significantly different from each other. Individual responses are given in figure 1 . 

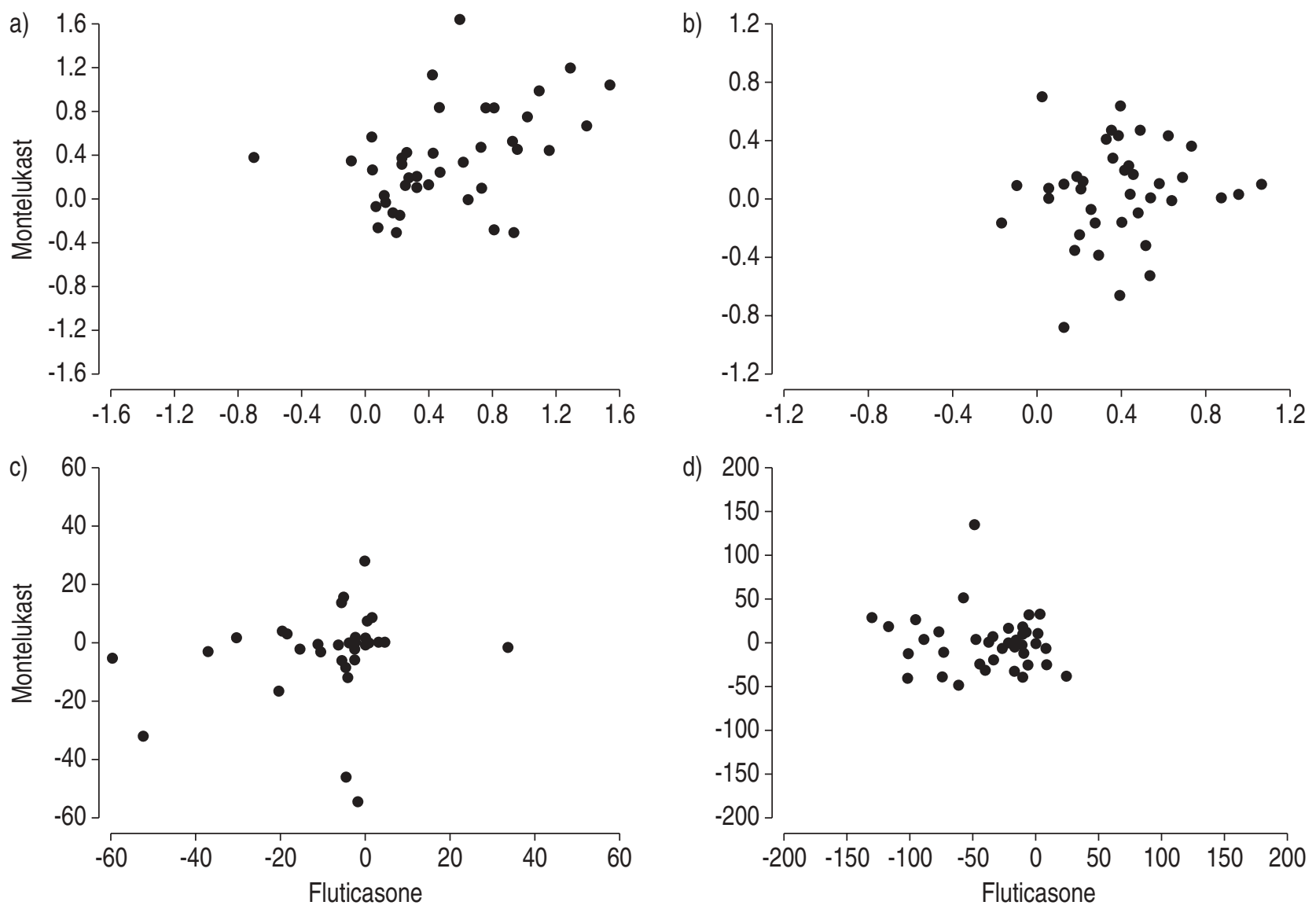

Fig. 1.- Individual changes over montelukast versus fluticasone treatment. Effects on a) lung function (forced expiratory volume in one second (FEV1), L), b) airway responsiveness to methacholine (provocative concentration causing a 20\% fall in FEV1 (PC20), in terms of the shift in doubling doses), c) sputum eosinophils (as per cent of nonsquamous cells) and d) the level of exhaled nitric oxide (parts per billion, at a flow rate of $50 \mathrm{~mL} \cdot \mathrm{s}^{-1}$ ) are shown.

\section{Lung function}

FEV1 significantly increased after treatment with fluticasone as well as montelukast $(\mathrm{p}<0.001$, each) (table 2). The respective changes were $0.50 \pm 0.07 \mathrm{~L}$ after fluticasone and $0.37 \pm 0.07 \mathrm{~L}$ after montelukast. The effects exerted by the two drugs were not significantly different from each other. FVC did not significantly change over both treatment periods.

\section{Bronchial responsiveness}

PC20 of methacholine increased significantly after treatment with fluticasone $(\mathrm{p}<0.001)$, the protective shift being $1.33 \pm 0.13$ doubling concentrations (table 2). In contrast, montelukast produced no significant effect, with an increase of $0.15 \pm 0.17$ doubling concentrations. The changes in $\mathrm{PC}_{20}$ differed significantly between both drugs $(\mathrm{p}<0.001)$.

\section{Induced sputum}

The percentage of eosinophils in induced sputum decreased significantly $(\mathrm{p}<0.001)$ after fluticasone (table 2), the average reduction being by factor 2.7 \pm 1.3 . Montelukast had no statistically significant effect on eosinophils, the respective factor being $1.4 \pm 1.3$. When comparing the effects of fluticasone

Table 2. - Results before and after the two 4-week treatment periods

\begin{tabular}{|c|c|c|c|c|c|c|}
\hline & \multicolumn{3}{|c|}{ Fluticasone } & \multicolumn{3}{|c|}{ Montelukast } \\
\hline & Pre & Post & p-value & Pre & Post & p-value \\
\hline FEV1 L & $2.68 \pm 0.09$ & $3.18 \pm 0.10$ & $<0.001$ & $2.75 \pm 0.09$ & $3.12 \pm 0.12$ & $<0.001$ \\
\hline $\mathrm{PC} 20 \mathrm{mg} \cdot \mathrm{mL}^{-1}$ & $0.178 \div 1.17$ & $0.449 \div 1.17$ & $<0.001$ & $0.196 \div 1.18$ & $0.217 \div 1.17$ & 0.39 \\
\hline Sputum eosinophils $\%$ & $4.9 \div 1.3$ & $1.8 \div 1.3$ & $<0.001$ & $3.2 \div 1.3$ & $2.3 \div 1.4$ & 0.16 \\
\hline Exhaled NO ppb & $54.8 \div 1.1$ & $26.7 \div 1.1$ & $<0.001$ & $52.0 \div 1.1$ & $48.7 \div 1.1$ & 0.36 \\
\hline Tryptase $\mathrm{pg} \cdot \mathrm{mL}^{-1}$ & $8.8 \div 1.4$ & $4.0 \div 1.4$ & 0.005 & $4.8 \div 1.4$ & $6.5 \div 1.4$ & 0.28 \\
\hline
\end{tabular}

Mean values and arithmetic $( \pm)$ or geometric $(\div)$ SEM are given. FEV1: forced expiratory volume in one second; PC20: provocative concentration causing a $20 \%$ fall in FEV1; NO: nitric oxide. 
and montelukast on sputum eosinophils, they were not statistically significantly different.

Tryptase levels in sputum supernatants decreased significantly after fluticasone $(\mathrm{p}<0.01$; table 2$)$, whereas the change after montelukast was not statistically significant. The changes in tryptase levels differed significantly between both treatments $(\mathrm{p}<0.05)$.

\section{Exhaled nitric oxide}

After fluticasone the level of exhaled NO at a flow rate of $50 \mathrm{~mL} \cdot \mathrm{s}^{-1}$ decreased significantly $(\mathrm{p}<0.01$; table 2), whereas after montelukast the change was not significant. The changes were also significantly different between treatments $(\mathrm{p}<0.001)$.

\section{Symptoms and use of supplemental salbutamol}

Complete diary data were available in 38 patients (table 3). Fluticasone, but not montelukast, led to significantly reduced daytime symptoms $(\mathrm{p}=0.05)$ compared to baseline. Both medications had no effect on night-time symptoms. The use of $\beta_{2}$-agonists decreased after both treatments $(p<0.05$ each). When compared between treatments, neither symptom scores nor the use of $\beta_{2}$-agonists showed a significant difference. Similar results were obtained when the analysis was restricted to patients who showed a symptom score of $\geqslant 0.5 \cdot \mathrm{day}^{-1}$ at screening.

\section{Peak flow measurements}

Complete data were available in 32 patients. The increase in morning PEF was $46.7 \pm 12.3 \mathrm{~L} \cdot \mathrm{min}^{-1}$ in fluticasone $(\mathrm{p}<0.05)$ and $14.0 \pm 7.1 \mathrm{~L} \cdot \mathrm{min}^{-1}$ in montelukast (nonsiginificant (NS); fig. 2). Corresponding increases for evening $\mathrm{PEF}$ were $31.2 \pm 7.0$ after fluticasone $(\mathrm{p}<0.05)$ and $5.7 \pm 6.8 \mathrm{~L} \cdot \mathrm{min}^{-1}$ after montelukast (NS).

\section{Discussion}

The present data demonstrate that a 4-week treatment with either montelukast or fluticasone in patients with moderate asthma led to a significant improvement in lung function that was similar for both treatments. In addition, the use of inhaled $\beta_{2}$-agonists was reduced by both fluticasone and montelukast. However, only fluticasone caused a

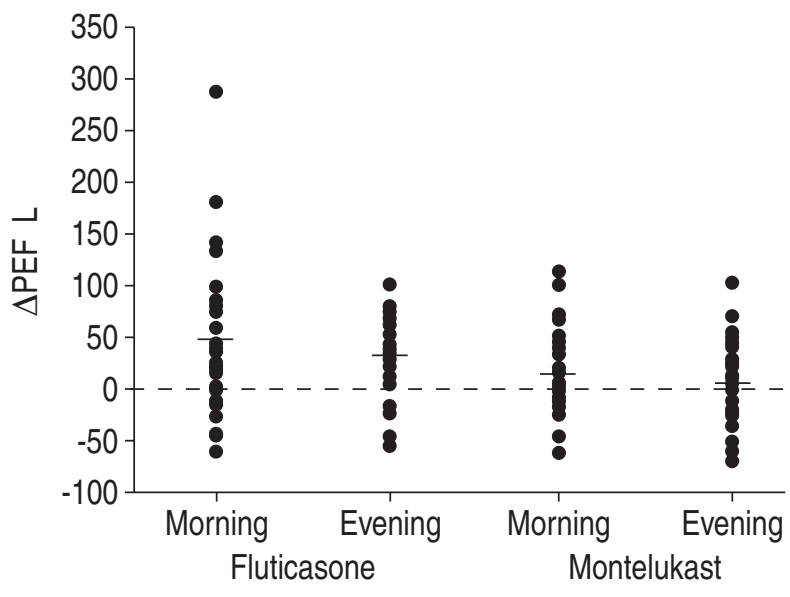

Fig. 2.-Individual changes in peak expiratory flow (PEF) over the treatment periods. Values were computed as mean values of 7-day periods before and at the end of treatment periods. The bars indicate the group mean values. Using a pairwise comparison, values were significantly higher $(\mathrm{p}<0.05)$ after fluticasone treatment than after montelukast for each morning and evening PEF.

significant reduction in airway responsiveness and inflammatory markers in induced sputum and exhaled air. These data suggest that, compared to $200 \mu \mathrm{g}$ fluticasone, $10 \mathrm{mg}$ montelukast daily had no antiinflammatory effect in the patients studied. However, the clinical improvement, as observed over 4 weeks, did not seem to be critically dependent on the antiinflammatory action.

The study was designed as a direct, head-to-head comparison of the effects of low-dose fluticasone and montelukast, with special emphasis on the simultaneous assessment of the patients' clinical state, lung function, airway responsiveness, and different noninvasive markers of airway inflammation. Several studies have been performed on the combined effect of an inhaled steroid plus an antileukotriene, but, to the best of the authors' knowledge, no studies are available that directly compare fluticasone and montelukast and include the scope of indices as measured here. To ensure that stable conditions had been reached, the duration of the treatment periods was set to 4 weeks. The superiority of antileukotrienes to placebo has been repeatedly demonstrated $[16,26]$, and the present study only enrolled patients in a stable clinical condition. Due to these facts, a placebo arm was omitted and efforts were made to raising the statistical power by achieving a crossover design in $\geqslant 40$ patients.

Previous studies comparing the effects of an

Table 3. - Symptom scores over treatment periods

\begin{tabular}{|c|c|c|c|c|c|}
\hline & Screening period & Fluticasone & p-value & Montelukast & p-value \\
\hline Daytime symptoms & $0.7 \pm 0.8$ & $0.4 \pm 0.7$ & 0.05 & $0.44 \pm 0.8$ & 0.08 \\
\hline Night-time symptoms & $0.35 \pm 0.5$ & $0.19 \pm 0.5$ & 0.17 & $0.27 \pm 0.5$ & 0.49 \\
\hline Salbutamol puff $\cdot$ day $^{-1}$ & $1.5 \pm 1.8$ & $0.8 \pm 1.7$ & $<0.001$ & $1.0 \pm 1.8$ & 0.02 \\
\hline
\end{tabular}

Data are presented as mean \pm SD of changes over fluticasone and montelukast treatment periods and as absolute values during the screening period. A score of 0 denotes no symptoms; a score of 4 denotes maximal symptoms, severe impairment of daytime activities, and no sleep during night-time. $\mathrm{n}=38$. 
antileukotriene with those of an inhaled corticosteroid in patients with asthma, showed some differences between both drugs in terms of clinical outcome parameters. Within a parallel group setting, 12 weeks of daily treatment with $400 \mu \mathrm{g}$ beclomethasone dipropionate (BDP) exerted larger effects on FEV1, symptom scores and the rate of asthma exacerbations than montelukast [27], but both drugs were clearly superior to placebo. Similarly, low-dose fluticasone was superior to montelukast with regard to lung function, symptoms and the use of rescue medication [18]. Analogous results were obtained regarding the effect of zafirlukast in comparison to those of BDP [28]. However, these studies did not assess the effect of the antileukotriene in terms of its anti-inflammatory properties.

The data from the present study did not indicate major differences between montelukast and fluticasone regarding their efficacy in terms of FEV1 or $\beta_{2^{-}}$ agonist use. The result probably has to be attributed to the steroid dose in relation to the patients' asthma severity. It should be kept in mind that symptom scores and the supplemental use of $\beta_{2}$-agonists were low at baseline, despite the fact that patients fulfilled the criteria of moderate asthma [1]. In case the equiefficacy of both drugs with regard to lung function and clinical state was due to a nonmaximal dose of fluticasone, this would render the differences in antiinflammatory action even more obvious.

Attenuation of eosinophilic inflammation by montelukast has been reported previously in a group of 16 patients with asthma [12]. At the same time, there was a significant reduction in daily asthma symptoms and the use of $\beta_{2}$-agonists. The percentage of sputum eosinophils significantly increased, when taking into account the change observed with placebo, where sputum eosinophils increased from $14.5-17.9 \%$. Similar effects have been reported with regard to the effect of montelukast or pranlukast on the number of sputum [29] or bronchial mucosal eosinophils under stable conditions [30]. Antileukotrienes are also capable of attenuating allergen responses. After a 3-day treatment with montelukast, early- and latephase allergen-induced bronchoconstriction were significantly reduced as compared to placebo [31]. No significant bronchodilation was observed $12 \mathrm{~h}$ after the last medication. However, as far as could be shown by sputum analysis in nine patients, the allergen-induced increases in eosinophil number and eosinophil cationic protein (ECP) level did not differ between montelukast and placebo. Anti-inflammatory effects have also been reported in children with asthma who showed a decline in the level of exhaled NO during treatment with montelukast compared to placebo [13]. The data of the present study revealed no significant effect of montelukast on sputum composition or NO levels and, at the same time, demonstrated the stability of these parameters and the patients' clinical condition in repeated measurements. With regard to FEV1 and PC20, stability was even part of the inclusion criteria in the present study.

The present study's data also differ from those obtained after reduction of the dose of inhaled beclomethasone during treatment with the antileukotriene pranlukast or placebo [16]. In this study, the level of exhaled NO increased after treatment with placebo, whereas it remained nearly unchanged after pranlukast. The present authors do not have an explanation for the discrepancies between studies, but it might be relevant that the present study data were obtained under stable conditions in adults with moderate asthma who did show low symptom scores at inclusion. At the least, the available data suggest that the effects of anti-leukotrienes are much more variable and, on average, lower than those of corticosteroids, and depend on the patient population and experimental protocol chosen.

In summary, the data of the present study indicate that 4-week treatments with either $100 \mu \mathrm{g}$ inhaled fluticasone b.i.d. or $10 \mathrm{mg}$ montelukast daily were equi-effective with regard to their effects on lung function in patients with moderate asthma. However, only fluticasone led to a significant reduction in airway responsiveness and to significant antiinflammatory effects on sputum eosinophils, tryptase concentrations, and the level of exhaled nitric oxide. It remains to be established whether the dissociation between effects as observed in the present study will have implications for the long-term outcome of the patients.

\footnotetext{
Acknowledgements. The authors thank O. Holz and H. Carnarius for helpful comments and S. Janicki, K. Paasch and $M$. Mücke for technical assistance.
}

\section{References}

1. National Institutes of Health. National Heart, Lung and Blood Institute. Global Initiative for Asthma. Publication 95-3659. Bethesda, MD, 1995.

2. Djukanovic R, Roche WR, Wilson JW, et al. Mucosal inflammation in asthma. Am Rev Respir Dis 1990; 142: $434-457$

3. Ulrik CS. Outcome of asthma: longitudinal changes in lung function. Eur Respir J 1999; 13: 909-918.

4. Sont JK, Van Krieken JHJM, Evertse CE, Hooijer R, Willems LN, Sterk PJ. Relationship between the inflammatory infiltrate in bronchial biopsy specimens and clinical severity of asthma in patients treated with inhaled steroids. Thorax 1996; 51: 496-502.

5. Pizzichini MMM, Pizzichini E, Clelland L, et al. Prednisone-dependent asthma: inflammatory indices in induced sputum. Eur Respir J 1999; 13: 15-21.

6. van Rensen ELJ, Straathof KCM, Veselic-Charvat MA, Zwinderman AH, Bel EH, Sterk PJ. Effect of inhaled steroids on airway hyperresponsiveness, sputum eosinophils, and exhaled nitric oxide levels in patients with asthma. Thorax 1999; 54: 403-408.

7. in't Veen JC, De Gouw HW, Smits HH, et al. Repeatability of cellular and soluble markers of inflammation in induced sputum from patients with asthma. Eur Respir J 1996; 9: 2441-2447.

8. Barnes PJ, Kharitonov SA. Exhaled nitric oxide: a new lung function test. Thorax 1996; 51: 233-237.

9. Lötvall J, Inman M, O'Byrne P. Measurement of 
airway hyperresponsiveness: new considerations. Thorax 1998; 53: 419-424.

10. Grönke L, Kanniess F, Holz O, Jörres RA, Magnussen $\mathrm{H}$. The relationship between airway responsiveness and airway inflammation depends on the duration of the asthmatic disease. Am J Respir Crit Care Med 2000; 161: A744.

11. Spada CS, Nieves AL, Krauss AHP, Woodward DF. Comparison of leukotriene $\mathrm{B}_{4}$ and $\mathrm{D}_{4}$ effects on human eosinophil and neutrophil motility in vitro. J Leukoc Biol 1994; 55: 183-191.

12. Pizzichini E, Leff JA, Reiss TF, et al. Montelukast reduces airway eosinophilic inflammation in asthma: a randomized, controlled trial. Eur Respir J 1999; 14: 12-18.

13. Bisgaard H, Loland L, Anhøj J. NO in exhaled air of asthmatic children is reduced by the leukotriene receptor antagonist montelukast. Am J Respir Crit Care Med 1999; 160: 1227-1231.

14. Dockhorn RJ, Baumgartner RA, Leff JA, et al. Comparison of the effects of intravenous and oral montelukast on airway function: a double blind, placebo controlled, three period, crossover study in asthmatic patients. Thorax 2000; 55: 260-265.

15. Laviolette M, Malmstrom K, Lu S, et al. Montelukast added to inhaled beclomethasone in treatment of asthma. Am J Respir Crit Care Med 1999; 160: 1862 1868.

16. Tamaoki J, Kondo M, Sakai N, et al. Leukotriene antagonist prevents exacerbation of asthma during reduction of high-dose inhaled corticosteroid. $\mathrm{Am}$ J Respir Crit Care Med 1997; 155: 1235-1240.

17. Kelloway JS, Wyatt RA, Adlis SK. Comparison of patients compliance with prescribed oral and inhaled asthma medication. Arch Int Med 1994; 154: 13491352.

18. Busse W, Raphael GD, Galant S, et al. Low-dose fluticasone propionate compared with montelukast for first-line treatment of persistent asthma: A randomized clinical trial. J Allergy Clin Immunol 2001; 107: 461-468.

19. Richter K, Kanniess F, Mark B, Jörres RA, Magnussen $\mathrm{H}$. Assessment of accuracy and applicability of a new electronic peak flow meter and asthma monitor. Eur Respir J 1998; 12: 457-462.

20. Quanjer PH, Tammeling GJ, Cotes JE, Pedersen OF, Peslin R, Yernault JC. Lung volumes and forced ventilatory flows. Report working party standardization of lung function tests, European Community for
Steel and Coal. Official statement of the European Respiratory Society. Eur Respir J 1993; 6: Suppl. 16, 5-40.

21. Jörres RA, Nowak D, Kirsten D, Grönke L, Magnussen H. A short protocol for methacholine provocation testing adapted to the Rosenthal-Chai dosimeter technique. Chest 1997; 111: 866-869.

22. Silkoff PE. Recommendations for standardized procedures for the online and offline measurement of exhaled lower respiratory nitric oxide and nasal nitric oxide in adults and children. Am J Respir Crit Care Med 1999; 160: 2104-2117.

23. Kharitonov S, Alving K, Barnes PJ. Exhaled and nasal nitric oxide measurements recommendations. Eur Respir J 1997; 10: 1683-1693.

24. Pin I, Gibson PG, Kolendowicz R, et al. Use of induced sputum cell counts to investigate airway inflammation in asthma. Thorax 1992; 47: 25-29.

25. Holz O, Jörres RA, Koschyk S, Speckin P, Welker L, Magnussen $\mathrm{H}$. Changes in sputum composition during sputum induction in healthy and asthmatic subjects. Clin Exp Allergy 1998; 28: 284-292.

26. Reiss TF, Sorkness CA, Stricker W, et al. Effects of montelukast (MK-0476), a potent cysteinyl leukotriene antagonist, on bronchodilation in asthmatic subjects treated with and without inhaled corticosteroids. Thorax 1997; 52: 45-48.

27. Malmstrom K, Rodriguez-Gomez G, Guerra J, et al. Oral montelukast, inhaled beclomethasone, and placebo for chronic asthma. Ann Intern Med 1999; 130: 487-495.

28. Laitinen LA, Naya IP, Binks S, Harris A. Comparative efficacy of zafirlukast and low dose steroids in asthmatics on prn $\beta_{2}$-agonists. Eur Respir J 1997; 10: 419s.

29. Minoguchi K, Kohno Y, Kobayashi H, Kihasa N, Sano Y, Adachi M. Potential antiinflammatory effects of montelukast on airways in asthmatics. Eur Respir $J$ 1999; 14: 121s.

30. Nakamura Y, Hoshino M, Sim JJ, Ishii K, Hosaka K, Sakamoto T. Effect of leukotriene receptor antagonist pranlukast on cellular infiltration in the bronchial mucosa of patients with asthma. Thorax 1998; 53: 835-841.

31. Diamant Z, Grootendorst DC, Veselic-Charvat M, et al. The effect of montelukast (MK-0476), a cysteinyl leukotriene receptor antagonist, on allergen-induced airway responses and sputum cell counts in asthma. Clin Exp Allergy 1999; 29: 42-51. 